\title{
Evolution of tobacco control studies at the National Cancer Institute
}

Over the past decade and a half, the National Cancer Institute (NCI) has supported an ambitious research programme with the goal of significantly reducing smoking prevalence in the United States. Initially, the NCI funded randomised trials consisting of interventions aimed both at preventing the uptake of smoking among adolescents and promoting successful cessation among adults. ${ }^{1}$ Findings from over 100 intervention trials continue to provide much new and important information about how to reach smokers and potential smokers. However, one of the major conclusions that one can draw from these studies is that largescale reductions in smoking prevalence are unlikely using interventions that are primarily directed toward the individual and delivered through traditional intervention channels. $^{2}$

This knowledge, coupled with the growing realisation that smoking behaviour is strongly influenced by one's social environment, meant that research strategies needed to be reconsidered. It also meant that the unit of analysis could no longer focus on the individual but had to include the larger community. The concept of multiple interventions delivered through multiple channels was tested in NCI's Community Intervention Trial for Smoking Cessation (COMMIT), a matched-pair, randomised trial of 22 small to medium sized communities. ${ }^{3}$ The intervention communities strove to implement the most promising service-based cessation approaches from the earlier research. COMMIT did not attempt to change community-wide policies per se but rather worked within the policy framework that existed within each community at the time the interventions were implemented. ${ }^{4}$ Although COMMIT did not achieve the kind of overall effectiveness that the public health community had hoped for, positive changes were observed between some pairs of communities. Furthermore, COMMIT did demonstrate significantly higher rates of quitting among light-to-moderate smokers ( $<25$ cigarettes/day) that, if achieved nationally, would translate into 1.2 million additional adults quitting. ${ }^{5}$

The findings from COMMIT and other tobacco control efforts led to the decision to continuing planning for NCI's next big step in its attempt to reduce smoking rates nationally-the American Stop Smoking Intervention Study for Cancer Prevention (ASSIST). The decision was buoyed by the success of other large-scale, comprehensive smoking control efforts primarily in Australia and Canada. ${ }^{6-9}$ and the early success demonstrated by the California Statewide Tobacco Control Programme. ${ }^{10}$ (California adopted the ASSIST model in 1990.) Data published by the NCI in this supplement to Tobacco Control clearly indicate that ASSIST is already having an impact on per capita cigarette consumption compared with the rest of the United States. " Per capita consumption was nearly identical in ASSIST and non-ASSIST states (excluding California) in 1993 when the ASSIST interventions began. By 1996 , however, ASSIST states were consuming $7 \%$ fewer cigarettes per capita. This reduction translates into $50 \mathrm{mil}-$ lion fewer packs of cigarettes consumed per month in the 17 ASSIST states.

A significant difference between the ASSIST demonstration project and the previous research designs funded by NCI has been the discarding of the randomised, controlled trial methodology in favour of surveillance systems that allow for time-series analysis designs comparing intervention and "control" communities. The appropriateintervention and these designs to community studies has been previously demonstrated. ${ }^{12}$ Such a design documented the impact of the media-led tobacco control programme in Australia, ${ }^{6}$ the impact of tobacco marketing practices on smoking initiation in adolescents ${ }^{13}$ and, as cited above, the initial success of the ASSIST programme.

The COMMIT trial, however, provided much more information than what was an appropriate study design for community studies. The careful analysis of the consensus data collected on COMMIT have been crucial to decisions on what types of interventions should be supported in statewide programmes. ${ }^{4}$ In this supplement the COMMIT study offers considerable insight into change in smoking behaviour. Three different analyses of the available data emphasise the effect of price on who participates in smoking and on who switches to lower price generic brands. ${ }^{14-16}$ These data support a growing literature that indicates the importance of changes in price consumption behaviour. ${ }^{17} 18$ Achieving an increase in state cigarette excise taxes is also a major goal in the ASSIST tobacco control programme. ${ }^{19}$ American consumers continue to have some of the most affordable cigarettes in the world. ${ }^{20}$

The COMMIT data also provides further validation that an individual's level of addiction determines the probability of successful quitting and thus the need to support development of tailored interventions to assist individuals who want to quit. ${ }^{21}$ The importance of the use of the nicotine patch as an aid to quitting was also validated in COMMIT with patch users more than twice as likely to succeed in quitting than those who did not use patches. ${ }^{22}$

Another COMMIT paper ${ }^{23}$ supports the growing body of evidence that workplace smoking policies not only reduce non-smoker exposure to environmental tobacco smoke but also reduce cigarette consumption and promote quitting behaviour. ${ }^{24}$ Clearly the achievement of smoke-free workplaces and smoke-free schools must be a major focus of any tobacco control programme, as they are in both California and the ASSIST states.

Finally, the science of tobacco control, like any field, is increasingly diverse and complex, as this supplement to Tobacco Control clearly illustrates. The science that guides tobacco control must address issues at all levels, whether it is the individual, the community, state, or the nation. Different research designs and methods may be used at different levels but, to achieve large-scale reductions in tobacco use, continued attention must be focused on those interventions that are effective in reaching large 
populations. The careful evaluation of state and national intervention programmes holds great promise for guiding future tobacco control efforts in the United States. And as new intervention technologies are assessed, we must ensure that this information is rapidly and systematically applied. Systematic coordination of research and intervention programmes has been a key feature of tobacco control efforts to date, and it remains an absolute necessity.

\section{RICHARD KLAUSNER}

31 Center Drive, MSC 2590,

Building 31, Room 11 A48

Bethesda, Maryland 20892, USA

email: klausner@helix.nih.gov

1 Shopland DR, Massey M, eds. Smoking, tobacco, and cancer program, 1985-1989 status report. Bethesda, Maryland: National Institutes of Health, National Cancer Institute, 1990. (NIH Publication No 90-3107.)

2 US Department of Health and Human Services. Strategies to control tobacco use in the United States. A blueprint for public health action in the 1990s. Smoking and Tobacco Control Monograph No 1. Bethesda, Maryland: National Institutes of Health, National Cancer Institute, 1991. (NIH Publication No 92-3316.)

3 Lichtenstein E, Wallack L, Pechacek T, eds. Community Intervention Trial for Smoking Cessation: COMMIT Special Issue. Int $O$ Commun Health Educ 1990-91;11:169-309.

4 US Department of Health and Human Services. Community-based interventions for smokers: the COMMIT field experience. Smoking and Tobacco Contions for smokers: the NOM. Bethesda, Maryland: Public Health Service, trol Monograph No . Bethesda, Maryland. Public Health SIH PubNational Institutes of

5 The COMMIT Research Group. Community Intervention Trial for Smokin Cessation (COMMIT): I. Cohort results from a four-year community ing Cessation (COMMIT): I. Cohort results from

6 Pierce JP, Dwyer T, Frape G, Chapman S, Chamberlain A, Burke N. Evaluation of the Sydney "Quit for Life" anti-smoking campaign. Part I: Achievement of intermediate goals. Med $\mathcal{f}$ Aust 1986;144:341-4.

7 Dwyer T, Pierce JP, Hannam CD et al. Evaluation of the Sydney "Quit for Life" anti-smoking campaign. Part II: Changes in smoking prevalence. Med $千$ A ust 1986;144:344-7.

8 Pierce JP, Macaskill P, Hill D. Long term effectiveness of mass media led anti-smoking campaigns in Australia. Am $\mathcal{f}$ Public Health 1990;80:565-9.
9 Mahood, G. Treating the tobacco epidemic like an epidemic: the road to effective tobacco control in Canada. In: Durston B, Jamrozik K, eds. Proeffective tobacco control in Canada. In: Durston B, Jealth, 1-5 April 1990. ceedings of the seventh world conference on tobacco and heallh, $1-5$.

10 Perth: Health Department of Western Australia, 1990-1991. Sacramento, Burns DM, Pierce JP. Tobacco use in California 1990-1961. Services, 1991.

11 California: Canfornia State Department of B Berry C, Wun L-M. Impact of the American Stop Silpin EA, Rosbrook, B, Berry (ASSIST) on cigarette consumption. Tobacco Control 1997;6(suppl 2):S12-16.

12 Salonen JT, Kottke TE, Jacobs DJ, Hannan PH. Analysis of communitybased cardiovascular disease prevention studies-evaluation issues in the Epidemiol 1986;15:176-82

13 Pierce JP, Lee L, Gilpin EA. Smoking initiation by adolescent girls 1944-1988. Lee L, Gilpin EA. Smoking initiation by adolising. $尹 A M A$ 1994; 271:608-11

14 Cummings KM, Lewit E, Shopland D. Use of discount cigarettes by smokers in 20 communities in the United States, 1988-1993. Tobacco Contro 1997;6(suppl 2):S25-30.

15 Cummings KM, Pechacek TF, Orlandi M, Lynn WR. Comparison of recen trends in adolescent and adult cigarette smoking behaviour and brand preferences. Tobacco Control 1997;6(suppl 2):\$31-37.

16 Lewitt EM, Hyland A, Kerrebrock N, Cummings KM. Price, public policy, and smoking in young people. Tobacco Control 1997;6(suppl 2):S17-24.

17 Kaiserman MI, Rogers B. Tobacco consumption declining faster in Canad than in the US. Am 7 Public Health 1991;81:902-4.

18 Towsend JL. Cigarette tax, economic welfare and social class patterns of smoking. Appl Econ 1987;19:355-65.

19 Manley M, Lynn W, Epps RP, Grande D, Glynn T, Shopland D. The American Stop Smoking Intervention Study for cancer prevention: an American Stop Smoking Intervention Study for

20 National Cancer Institute. The impact of cigarette excise taxes on smoking among children and adults. Summary report of a National Cancer Institute among children and adults. Summary report of a National Cancer

21 Farkas AJ, Pierce JP, Zhu SH, Rosbrook B, Berry C, Kaplan RM. Addiction versus stages of change models in predicting smoking cessation. Addiction 1996;91:1271-80

22 Cummings KM, Ockene JK, Hymowitz N, Manley M. Use of the nicotine skin patch by smokers in 20 communities in the United States, 1992-1993. Tobacco Control 1997;6(suppl 2):S63-70.

23 Glasgow RE, Cummings KM, Hyland A. Relationship of worksite smoking policy to changes in employee tobacco use: findings from COMMIT. policy to changes in employee tontrol 1997;6(suppl 2):S44-48.

24 Stilman FA Becker DM Swank RT, et al Ending smoking at the Johns Hillman FA, Becker DM, Swank RT, et al. Ending smok
Hopkins medical institutions. $¥ A M A$
$1990 ; 264: 1565-9$.

25 Sorenson G, Rigotti N, Rosen A. Effects of a worksite non-smoking policy: evidence for increased cessation. Am $\mathcal{F}$ Public Health 1991;81:202-4. 